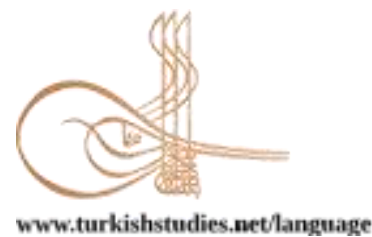

Turkish Studies - Language and Literature

eISSN: 2667-5641

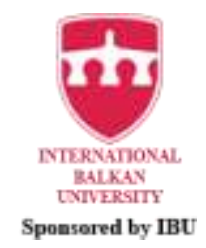

ResearchArticle / Araştırma Makalesi

\title{
Kırgız Türkçesinde Yansıma Kelimeler ve Onlardan Söz Türetme Yolları
}

OnomatopiecWords in Kyrgyz Turkish and Ways to Derive Them

\begin{abstract}
AidinaTazhieva*
Abstract: Onomatopoeic words have an important place in the vocabulary of Turkish. Onomatopoeic words are the words that imitate or define the sounds or visions coming from any living or non-living creatures around us. Such words help to convey an idea exactly and comprehensively. Kyrgyz Turkish is also rich in onomatopoeic words. Onomatopoeic words in Kyrgyz Turkish analyzed into two categories as Sound Onomatopoeic Words and Shape Onamatopaeic Words. Sound onomatopoeic words emerge through mimicking all kinds of sounds in nature. Shape Onomatopoeic words appear by depicting apperances and movements. These words are very common in spoken language. Also used in literary works, folk tales, epics, proverbs and idioms. This is because it gives clarity to any thought and adds vitality to the narration. Onomatopoeic words have regular structure in terms of sound, shape, task, function and operation. These structures formed an independent and seperate word group in Kyrgyz Turkish. They have many features in terms of sound, shape and meaning. Onomatopoeic word in Kyrgyz Turkish are used in four ways. 1. İn the form of root. 2. Reflection repetition forms. 3. With auxiliary verbs. 4. With various suffixes. Since the reflections have a structure that expands from the monosyllabic roots and grows with derivatives, the forms derived from various supplements are widely used in our language. İn this study, Onomatopoeic words in Kyrgyz Turkish are exemined in terms of structure knowledge.
\end{abstract}

Structured Abstract: Onomatopoeic words are formed through depiction and imitation of the sounds and appearances of all living beings in nature. Onomatopoeic words are an important group of words in the language. People can express the sound and appearance they hear in everyday life in the best onomatopoeic words. Onomatopoeis adds vitality to the narration. In fact, children start talking with reflections. Reflections that add movement, liveliness and a different color to language have their own order and certain language rules. Reflection words, which are used frequently in the spoken language, along with the literary works, have also been included in the literature as elements that beautify the expression and give details.

Onomatopoeic words in Kyrgyz Turkish are traditionally examined under two headings. Onomatopoeic words based on sound imitation are Sound Onomatopoeic Words, and the onomatopoeic words based on the depiction of the image are Shape (Appearance) Onomatopoeic Words.

\footnotetext{
*Yüksek lisans öğrencisi, Denizli Pamukkale Üniversitesi, Edebiyat Fakültesi, Çağdaş Türk Lehçeleri ve Edebiyatları Bölümü

Master's student, Denizli Pamukkale University, Faculty of Literature, Department of Contemporary Turkish Dialects and Literature

ORCiD 0000-0001-9286-8461

aydanka.mir@mail.ru

Cite as/ Atıf: Tazhieva, A. (2020). Kırgız Türkçesinde yansıma kelimeler ve onlardan söz türetme yollar1.TurkishStudies-Language, 15(2), 843-865. https://dx.doi.org/10.29228/TurkishStudies.40606

Received/Geliş:16 January/Ocak 2020

Accepted/Kabul:20 June/Haziran 2020

Checkedbyplagiarism software

Copyright $(\odot)$ INTAC LTD, Turkey

Published/Yayın: 27 June/Haziran 2020

CC BY-NC 4.0
} 
Reflections are words that imitate or portray the sounds of living or inanimate beings around us. They emerge as a result of translating various sounds in nature into speech language. Therefore, we do not get the same sounds of nature, but approximate similar ones as our language allows. Such words always protect themselves and remain alive in the spoken language, as they have equivalents in nature. Thus, it has been used for centuries and continues to enrich further by diversifying throughout history.

"Sound Onomatopoeic words" are not exactly the equivalent of sounds in the outside world, they are similar only reflected in the way human language can. Therefore, sound onomatopoeic words are an approximate imitation of sounds, not complete. In this case, it is very natural that the same or similar onomatopoeic words are seen in other languages. But one expresses the voices he hears or perceives in his own language according to his personal and cultural characteristics. In other words, the source of sound reflective words in the languages of the world is common, but it is named according to the rules of the language to which it belongs when naming. Each society expressed its voices in nature according to the grammatical structure, accumulation and cultural characteristics of its language. Besides onomatopoeic words based on sound, there are also reflections that occur due to their visual sense. In this case, it is very natural that the same or similar onomatopoeic words are seen in other languages. But one expresses the voices he hears or perceives in his own language according to his personal and cultural characteristics. In other words, the source of sound reflective words in the languages of the world is common, but it is named according to the rules of the language to which it belongs when naming. Each society expressed its voices in nature according to the grammatical structure, accumulation and cultural characteristics of its language. Besides onomatopoeic words based on sound, there are also reflections that occur due to their visual sense.

Onomatopoiec words expand from monosyllabic roots and grow with derivatives. The aim of the study is to examine the reflection words in Kyrgyz Turkish in terms of structure knowledge, to distinguish their suffixes and origins.

1. Studies on Onomatopoeic words in Kyrgyz Turkish are limited. There has always been a lack of resources and insufficient information.

2. Onomatopoic words are many in Kyrgyz Turkish.

3. Most reflections are used in the form of derivatives, not root.

Onomatopoeic words in Kyrgyz Turkish are not used much in root form. The dilemmas, the forms derived by various attachments, or formed with the help of auxiliary verbs are used quite a lot in our language. In fact, the existence of such a root is revealed due to such uses. In Kyrgyz Turkish, the root of reflection is significantly lean and in a quandary format.

In our research, library scanning, dictionary and library work scanning, filing and cataloging methods were used in general and field study was done.

Based on the examples given above, we can make the following assessments: The most commonly used attachments to derive names from onomatopoeic words roots are $+(\mathrm{A}) \mathrm{k},+(\mathrm{I} / \mathrm{U}) \mathrm{k},+\mathrm{Ir} / \mathrm{Ur}$ attachments. + $\mathrm{Il} / \mathrm{Ul},+\mathrm{Iss} / \mathrm{Uss},+\mathrm{GU},+\tilde{\mathrm{n}},+\mathrm{k},+\mathrm{GAk},+\mathrm{kAn}$ and $+\mathrm{t}$ attachments were also used to produce fewer words. From the examples we obtained, it is possible to say that the name derivation system from the words reflected in the action is less used, and more verbs are derived. Some attachments that we think are name-derived only reinforce the meaning. Reflection is done with these attachments or boosters to show that sound is used higher, more accentuated, etc. The most commonly used attachment in the type of verb from image words is +A /O-, +kIr /kUr, +lA /dA/ tA-, +Ay/ Iy-, attachment. This attachment is followed by +Da attachment. Subsequent attachments are not as busy as these two attachments +A / I / O/ U-, +çAy /çIy-, +rA-/+rO-, AlA-.

According to the result, the reflections are more suitable for verb scans with the attachments they receive as name roots. Additional is used to strengthen more meaning in name production. The attachments brought in cause a little change. For example: like shing+ir. In this respect, it will be possible to indicate that onomatopoeic words contribute to word production, if not as important as other names, as indispensable elements of language.

Keywords: Contemporary Turkish Dialects, Kyrgyz Turkish, Onomatopoeic, Sound Onomatopoeic Words, Shape Onomatopoeic Words, Sound, Structure 
Öz: Yansıma sözcükler Türkçenin söz varlığı içerisinde önemli bir yere sahiptir. Çevremizdeki canlı ya da cansız varlıkların çıkardıkları seslerin taklidini veya onların görünüşlerini tasvir eden kelimeler, yansıma kelimelerdir. Bu tür kelimeler herhangi bir düşünceyi tam ve kesin olarak vermekte kolaylık sağlar ve anlatıma canlılık katar. Kırgız Türkçesi yansıma kelimeler bakımından çok zengindir. Kırgız Türkçesinde yansımalar genellikle ses yansımalı kelimeler (tabış tuurandı sözdör) ve biçim yansımalı kelimeler (eles tuurandı sözdör) olarak iki başlık altında incelenmektedir. Ses yansımalı kelimeler doğadaki her çeşit sesleri taklit etme yoluyla ortaya çıkar. Biçim yansımalı kelimeler ise görünüm ve hareketleri tasvir etme yoluyla ortaya çıkmaktadır. Bu tür kelimelere konuşma dilinde oldukça sık rastlanır. Aynı zamanda yansımalar edebi eserlerde, halk hikayelerinde, destanlarda, atasözleri ve deyimlerde de sık kullanılırlar. Çünkü yansımalar herhangi bir düşünceye netlik kazandırır ve anlatıma canlılık katarlar. Yansımalar ses, şekil, görev, fonksiyon ve işleyiş açısından düzenli bir yapıya sahiptir. Bu yapılar Kırgız Türkçesinde bağımsız ve ayrı bir kelime grubunu oluşturmuştur. Onlar ses, şekil ve anlam bakımından pek çok özelliği bünyesinde taşırlar. Kırgız Türkçesinde yansımalar dört şekilde kullanlır. 1. Kök halinde. 2. İkilemeli yansımalar halinde. 3. Yardımcı fiillerle beraber. 4. Çeşitli eklerle türemiş halinde. Yansımalar tek heceli köklerden giderek genişleyen ve türetmelerle büyüyen bir yapıya sahip olduğu için çeşitli eklerle türemiş biçimleri dilimizde oldukça fazla kullanılmaktadır. Bu çalışmada Kırgız Türkçesindeki yansıma kelimeler yapı bilgi açısından incelenmektedir.

Anahtar Kelimeler: Çağdaş Türk Lehçeleri, Kırgız Türkçesi, Yansımalar, Ses Yansımalı Kelimeler, Biçim Yansimalı Kelimeler, Ses, Yapı

\section{Giriş}

Kırgız Türkçesinde "Taklidî Kelimeler" (TuurandıSözdör) olarak bilinen yansıma kelimeler için Türkiye Türkçesinde çok çeşitli terimler kullanılmaktadır. Geçmiş yıllarda "taklîdî kelime" terimine karşılık olarak "yankı kelime" (Bayrav, 1969); "ses yansımalı kelimeler" (Zülfikar, 1995); "yansılama” (Banguoğlu, 1986); "yankılık” (Tekin, 1977); "onomatopée" (Eren, 1951); "tabiat taklidi söz" (Tuna, 1947); "ses taklidi" (Topaloğlu, 1989); "ses taklidi sözcükler, yansımal sözcükler" (Hengirmen, 1995); "yansıma sözcük" (Aksan, 1983) ve "yansıma" (Vardar, 1980; DilbilimTS; Hatiboğlu, 1978; Gencan, 1947) gibi farklı terimler kullanılmaktadır.

$\mathrm{Bu}$ terimlerin içinden yansıma terimi son yıllarda bu konuda yapılan dil çalışmalarında giderek yaygınlık kazanmaktadır. Araştırmacıların genellikle hem fikir olduğu konu ise yansıma kelimelerin, tabiat seslerini taklit ve tasvir yolu ile ortaya çıkmış olmasıdır.

Z. Korkmaz yansımaları ses yansımalı kelimeler insanoğlunun tabiattaki canlı cansız bütün varlık ve nesnelere ait sesleri benzetme ve taklit yolu ile çıkardı̆̆ seslerden oluşmaktadır (Korkmaz, 2009: 1188) şeklinde tanımlar. T. Banguoğlu tabiat seslerini tasvir veya kabataslak taklit ederek meydana gelen ses toplulukları (Banguoğlu, 2015: 402) olarak tanımlarken, Vecihe Hatiboğlu tabiat seslerini andıran kelimeler (Hatiboğlu, 1978: 133) olarak açıklamıştır. Dilbilgisi sözlüklerinde ise hemen hemen aynı tanımlar geçmektedir. Berke Vardar dış gerçeklik düzleminde var olan ses ya da gürültü̈leri, işitimsel izlenimi yansıtacak biçimde aktaran, adlandırılan gerçeği ses öykünmesi yoluyla belirten dilsel öğe (Vardır, 2002: 216)Kamile İmer doğa ve hayvan seslerine benzer seslerle yapılan, görüntüleri işitimsel bir izlenim yansitacak biçimde aktaran, bir gerçeği ses öykünmesi yoluyla belirten dilsel öğe (İmer, 2011: 262) olduğu görüşündedir.

Hamza Zülfikar ise Ses Yansımal Kelimeler terimini kullanmasına rağmen diğer tanımlardan farklı olarak yansima kelimelerin insanın tatma, koklama, duyma, görme ve dokunma duyularıyla algıladı̆̆ tabiattaki canlılık ve hareketliliğin adlandırılmasıyla (Zülfikar, 1995: 1) oluştuğunu vurgulayarak, sadece ses ve duyma duyusuna bağlamadan, diğer duyularla da ilişkilendirmiş ve yansıma terimine geniş bir anlam yüklemiştir.

Yansıma kelimeler, doğadaki canlı cansız bütün varlıkların seslerini ve görünüşlerini tasvir ve taklit etme yoluyla oluşurlar. Fakat bu yansımalar diş dünyadaki seslerin tam dengi değildir sadece insan dilinin elverdiği şekilde yansıtılmış benzerleridir. Dolayısıyla yansımalar seslerin tam 
değil yaklaşık bir taklididir. Bu durumda aynı ya da benzer yansımaların başka dillerde de görülmesi çok doğaldır. Fakat insan duyduğu ya da algıladığı sesleri kendi kişisel ve kültürel özelliklerine göre kendi konuştuğu dilde ifade eder. Yani dünya dillerindeki yansıma kelimelerin kaynağ 1 ortaktır ancak isimlendirilirken ait olduğu dilin kurallarına göre isimlendirilmiştir. Her toplum doğada duyduğu sesleri dillerinin gramer yapısına, birikimine ve kültürel özeliklerine göre ifade etmiştir. Yansıma kelimeler dilde önemli bir grubu oluşturur. İnsanlar günlük hayatta duyduğu ses ve görünüşleri en iyi yansımalı kelimelerle ifade edebilir. Yansıma kelimeler anlatıma canlılık katar. Hatta çocuklar ilk konuşmaya kendilerine göre anlamlandırdığı yansımalarla başlar. Özellikle halk ağzında kullanılan ses yansımaları, anlaşma aracı olarak sık sık kullanılan sözcük gruplarıdır. Yansımalar yazı dilinde daha az kullanılırken, halk ağzında geniş biçimde kullanımaktadır. Yansıma kelimeler kök olarak isim kökü karakterindedir (Banguoğlu, 2015: 402). Ancak getirilen çeşitli eklerle isim, sıfat, zarf ve fiil görevinde kullanılabilir.

\section{Kırgız Türkçeinde Yansımalar Hakkında Genel Bilgi}

\subsection{Kırgız Türkçesinde Yansımalar}

Kırgız Türkçesinde yansıma kelimeler ortak ve herkes tarafından benimsenmiş "TuurandıSözdör / Taklidî Kelimeler" başlığı altında incelenerek, tek bir terimle kullanılmaktadır. Yansıma kelimelerin tanımı hakkında bütün dilbilimciler aynı fikirdedirler. İbrayimAbduvaliev (2008: 342), Sarıbay Kudaybergenov (1980: 281), KarbozDiykanov (1990: 294), BolotYunusaliev (1959), BübüynaOruzbayeva (2009: 466), Aygül Akunova (2009: 77) ve diğer Kırgız bilim adamları yansımaları genel olarak "Caratılıştagı ar kanday tabıştardı tuurap cana kıymıl araketti, al abaldl, sırtkı körünüştü elestetip aytkan sözdör tuurandı sözdör dep atalat / Doğadaki her türlü sesleri taklit ederek ve hareketi, hali, dış görünüşleri tasvir ederek söylenilen kelimelere, taklidi kelimeler denir" şeklinde tanımlar.

Bilim adamları Kırgız Türkçesinde yansımaları geleneksel olarak iki gruba ayırarak incelerken son zamanlarda üç gruba ayırarak ele almaktadırlar. Kırgız Türkçesindeki ses taklidine dayalı olan yansıma kelimeler "Tabış Tuurandı Sözdör / Ses Yansımalı Kelimeler"görüntü tasvirine dayalı olan yansımalar ise "Eles Tuurandı Sözdör / Biçim (Görünüş) Yansımalı Kelimeler" olarak iki grup altında ele alınmıştır (Kudaybergenov, 1980: 281-286). Daha sonraki bazı çalışmalarda sezgi ve hisse dayalı olan sözcüklerin Tuyum Tuurandı Sözdör / Sezgi Yansımalı Kelimeler" başlığı altında yansımaların üçüncü grubunu oluşturduğu görülmektedir (Dıykanov, 1990: 294). Ancak İbraim Abduvaliyev, Taşbolot Sadıkov (1997, 258-268) ve BübüynaOruzbayeva (2009: 466) Ses ve Biçim Yansımaları olarak ikiye, daha sonra Biçim Yansımaları "Körü̈̈ Seziminin Negizinde / Görme Duyusuna Dayanan Biçim Yansımaları" ve "Tuуии Seziminin Negizinde / Sezgiye Dayanan Biçim Yansımaları"olarak tekrar kendi içinde ikiye ayırmışlardır.

Ses Yansımalı Kelimeler canlı veya cansız varlıklardan ve doğanın çeşitli olaylarından çıkan sesleri taklit ederek oluşan kelimelerdir. Örnek: kıt kıt külüü (çocuğun gülmesi), maaroo(kuzuların melemesi), tars(tüfekten çıkan ses), şarkıratma(şelale) v.s. 344-345).

Ses Yansımalı Kelimelerneyi taklit ettiğine göre dört gruba ayrılır (Abduvaliyev, 2008:

1) İnsanların çıkardığı sesler: kübür-şıbır, bırs, ha-ha, v.s.

2) Hayvanların çıkardığı sesler: ars-ars, kükük, mö̈, maaız-ız.v.s.

3) Cansız nesnelerin çıkardığı sesler: tars, kars, kaçır-kuçur, düp, v.s.

4) Doğa olaylarına ilişkin sesler: çart-çurt, şatır-şutur, şar v.s.

Biçim Yansımalı Kelimeler canlı veya cansız varlıkların görünüşünü ve onların hareketini tasvir etmekle oluşan kelimelerdir. Bu tür kelimeler görme duyusuna ve sezgi duyusuna dayanan 
biçim yansımalar olarak ikiye ayrılır. Görme duyusuna dayanan biçim yansımalar hissettiğimiz değil gördüğümüz şeylerin tasviridir. Kelimeyi duyduğumuzda görüntü gözümüzde canlanır. Örnek: saksaygan(saçları dağınık, taranmamış), deldeり kulak (büyük kulak) v.s. Sezgiye dayanan biçim yansımalar ise insanın vücut, koku, tat hisleri sayesinde ortaya çıkan kelimelerdir. Örnek: c1tıbur etüü (aniden gelen koku), söögüzır zırooruu (kemik ağrısı), cürögübolkbolksoguu (kalb atış1) v.s. 282).

Biçim Yansımalı Kelimeler neyi tasvir ettiğine göre ikiye ayrılır (Kudaybergenov, 1980:

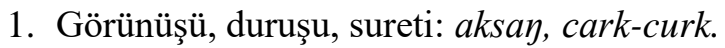

2. Hareketi, hali: selt, darday-darday.

Kırgız Türkçesi yansıma kelimeler bakımından çok zengindir. Yansıma kelimeler özellikle halk ağzında oldukça fazladır. Yansımalar sözlü konuşmadaki anlatımı daha da canlı yaparken, edebiyatta ise bahsedilmekte olan konunun daha kesin ve açık olmasını sağlar. Dolayısıyla sözlü edebiyatta, folklor ürünlerinde, halk destanı, tekerleme, atasözü ve deyimlerinde çok kullanılmakla beraber ilmi çalışmalarda ve resmi evraklarda özel isim olarak kalıplaşmış yansımalar hariç kullanımları söz konusu değildir.

Yansımalar hem ses hem yapı hem anlam bakımından diğer kelime türlerinden farklıdır. Ünlü ya da ünsüz tek bir sesin değişimi ile kelimenin anlamı tamamen değişebilir. İsim, fiil, zarf, sıfat ne olursa olsun her zaman kendi özelliğini korur. Başka hiçbir kelime grupları söz türetme yolları ile bir yansıma olamaz. Fakat bir yansıma isim de olur, fiil de. Bu süreçte de yansımalığını kaybetmez, kelimenin sonuna ne gibi bir ek gelirse gelsin kökü her zaman bir taklitten oluşan yansımadir.

\subsection{Kırgız Türkçesinde Yansımaların Yapısal Özellikleri}

Kırgız Türkçesinde ses yansımalı kelimeler de, biçim yansımalı kelimeler de yapı bakımından basit (cönököy) ve birleşik (tataal) olarak ikiye ayrılır (Abduvaliyev, 2008: 346; Üsönaliyev, Ömüraliyev, 2007: 65).

Basit yansıma kelimeler bir tek kelimeden oluşur. Onlar çoğu zaman sesin ya da görünüşün aniden ortaya çıkmasını ve kısa süreliğini gösterir. Genelde et-, de-, koy-, kll-yardımcı fiilleri ile birlikte kullanılır. Örneğin tars et-, çank de- v.s. (Turgunbayev, 2012: 33)

Basit Ses Yansımalı Kelimeler yapısına göre ikiye ayrılır. olurlar.

1) $\mathrm{V}(a)$; VC (ov); CV (ba); CVC (düp, şak, tak); CVCC (tars, bors) şeklinde tek heceli

2) Ek alır, kelime türetirler: şarkıratma, dübürt, kükük.

Basit Biçim Yansımalı Kelimeler de yapısına göre ikiye ayrılır.

1). Genelde CVC ve CVCC şeklinde olur: şıp, cark.

2). Ek alır, kelime türetilir: ürpöygön, saksagay.

Birleşik yansımalar ise iki ve daha fazla sözcüklerden oluşur. Onlar taklit edilen sesin ya da görünüşün kesintisiz olduğunu, tekrarlandığını veya uzadığını gösterir (Abduvaliyev, 2008: 346).

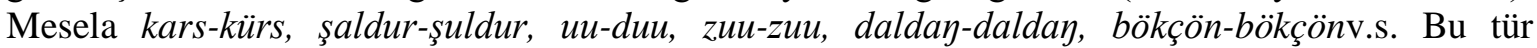
kelimeler Türkiye Türkçesinde ikilemeler olarak bilinir. İkilemeli yansımalar, iki ögesi de aynı sözcükten oluşan tekrarlamadan ya da anlamı yakın veya karşıt olan eşsesli sözcüklerden oluşur. İkilemeler anlatımı zenginleştirir, süreklilik açısından doğal sese veya harekete çok daha yakın olmasını sağlar. 
Birleşik Ses Yansımalı Kelimeler yapısına göre iki gruba ayrılır.

1). İki ögesi de aynı sözcükten oluşan yansımalar: kıtır-kıtır.

2). Eş anlamlı veya zıt anlamlı eşsesli sözcüklerden oluşan yansımalar: çart-çurt. 1980: 282)

Birleşik ses yansımalı kelimeler anlamına göre üçe ise üçe ayrılırlar (Kudaybergenov,

1) İki sözcüğün ikisi de anlamlı olanlar: kıykıldap-çıykıldap

2) İki sözcügü̈n biri anlamsız olanlar: şak-şuk

3) İki sözcüğün ikisi de anlamsız olanlar: $ı z ı \eta-k ı z ı \eta ~$

Birleşik Biçim Yansımalı Kelimeler yapısına göre iki gruba ayrılır.

1) İki ögesi de aynı sözcükten oluşan yansımalar: mölt-mölt.

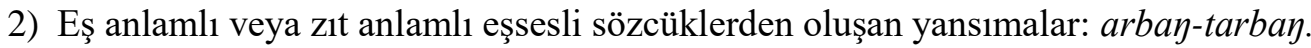

\section{Kırgız Türkçesinde Yansıma Kelimelerden Söz Türetme Yolları}

Ses yansımaları, doğadaki çeşitli sesleri konuşma diline aktarması sebebiyle başı başına sözcük yapımı içerisinde özel bir yere sahiptir. Ses yansımaları tamamen taklit sonucu ortaya çıkarlar ve dilimizin nisbetinde tam değil yaklaşık olanlarını veya benzerlerini elde ederiz. $\mathrm{Bu}$ yüzden esasında uydurma sözcük olsalar da dilimizin söz varlığının zenginleşmesinde oldukça büyük önem taşırlar. Bu sözcükler, kök halinde ekleme dışı sözcük yapımı yoluyla dilimize girer, daha sonra ekleme yoluyla yapım ve çekim ekleriyle çeşit çeşit kelimeler türetirler. Dolayısıyla onlar isim, sıfat, zarf ve fiil olabilmektedirler. Yansıma sözcükler ikileme şeklinde bir araya gelerek de sözcük yapımı oluşturmaktadır. Yansımaları, tek heceli köklerden giderek genişleyen ve türetmelerle büyüyen bir yapıya sahip oldukları için yapı bilgisi açısından Kökler ve Türevler olarak iki başlık altında incelememiz doğru olacaktır.

\subsection{Kökler}

Kırgız Türkçesinde yansımalar kök halinde fazla kullanılmaz. İkilemeli biçimleri, çeşitli eklerle türemiş biçimleri ya da yardımcı fiillerin yardımıyla kurulmuş biçimleri dilimizde oldukça çok kullanılmaktadır. Hatta bu gibi kullanımlardan dolayı böyle bir kökün varlı̆̆ı ortaya çıkmaktadır.

Birincil biçimler yansımaların en küçük tek heceli parçasıdır. Anlamlı olarak yalın durumunda ve ikilemeli biçimlerde görülür. Kırgız Türkçesinde birincil biçimlerin çoğu tek başına anlamlı birer isim'dir. Tek başına anlamlı fiiller ise az sayıda kullanılmaktadır. Fiil olarak kullanımların çoğu çeşitli eklerle türeyerek, yardımcı fiillerle veya öteki fiillerin yardımıyla oluşur.

\subsection{1. İsim Görevinde Kullanımları}

Yansımaların çoğu genel olarak isim yapısındadır. Dolayısıyla birincil biçimlerin çoğu da isim durumundadır. Ancak kalıplaşmış birer anlamlı isim olarak sayıca çok fazla değillerdir. Kırgız Türkçesinde yansımaların yalın hali değil, türemiş, ek almış veya yardımcı veya diğer fiillerle kurulmuş biçimleri kullanımda daha çok tercih edilmektedir.

Tek başına, herhangi bir ek almadan, yalın durumda kullanılan kalıplaşmış isim görevinde birincil biçim yansımalar anlamlı olarak ad ve sıfat görevinde kullanılmaktadır.

car : İlan, duyuru, bildiri, haber (Arıkoğlu vd., 2018: 515).

çuи :Gürültü, kavga (Arıkoğlu vd., 2018: 760). 
çır : 1. Kavga. 2. Kavgac1, huysuz kimse (Arıkoğlu vd., 2018: 731).

day :1. Şohret, nam, ün. 2. Belli, açık, bilinen (Arıkoğlu vd., 2018: 781).

dии : 1. Gürültü, şamata 2. Kavga, dövüş, savaş 3. Söylenti, söz. (Arıkoğlu vd., 2018: 841).

düy : 1. Şohret, nam, ün. 2. Söylenti, laf, dedikodu. (Arıkoğlu vd., 2018: 845).

Aynı şekilde kök halinde kalıplaşmış isim olarak ikilemeli yansımalar da vardır.

çuru-çuu : Gürültü, patırtı (Arıkoğlu vd., 2018: 760).

kürü-güü : Gürültü (Arıkoğlu vd., 2018: 1473).

ии-duи : Uğultu (Arrkoğlu vd., 2018: 2169).

ızı-çuи : Gürültü, patırtı (Arıkoğlu vd., 2018: 982).

Çocuk dilinde kullanılan yansımalar kök halinde olur ve çoğu zaman ad görevinde kullanılır. Fiilleştirilirken yardımcı fiillerle kullanılır.

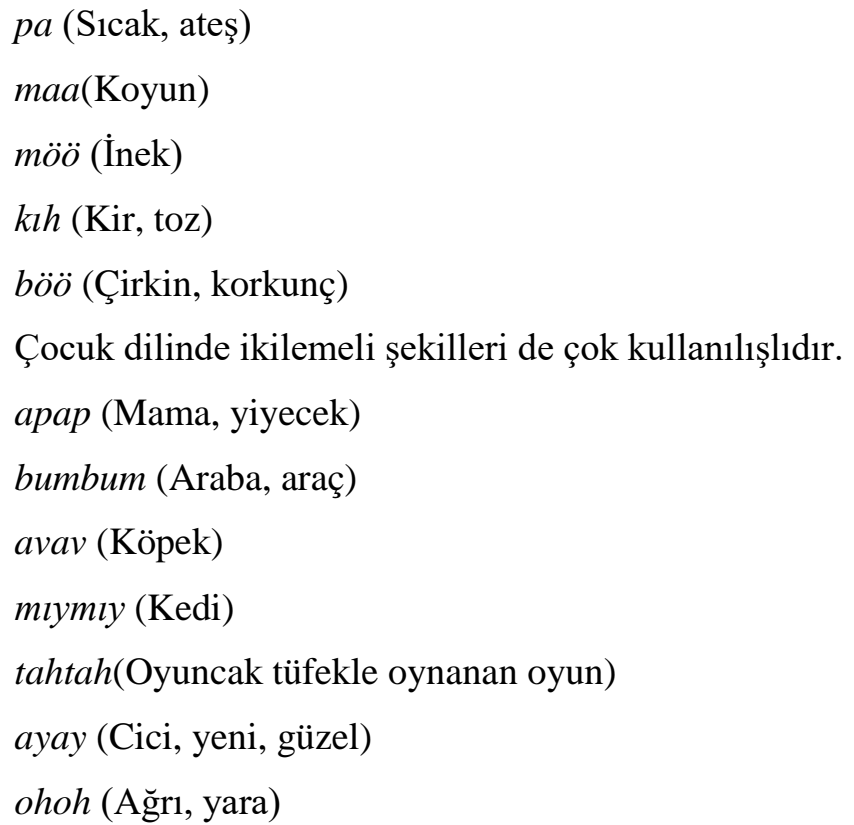

\subsubsection{Fiil Görevinde Kullanımları}

Kırgız Türkçesinde kök halinde yansımalar fiil olarak çoğunlukla yardımcı ve diğer fiillerle kullanılıyor. Kök halinde doğrudan fiil olarak kullanımları yansımalı filler azdır.. Türkiye Türkçesiyle ilgili Hamza Zülfikar'ın birincil durumda yansımalı fiiller konusunda verdiği örneklerin bazıları Kırgız Türkçesinde de kullanılmaktadır. Örneğin, cır- (Yırtmak, -Dz); cırt(Yırtmak, -To); çak- (Vurarak sokmak, yerleştirmek, TSöz), Kırgız Türkçesinde "vurarak kırmak, parçalamak" (Arıkoğlu vd., 2018: 683) anlamında kullanılıyor; çap- (Kesmek, TENNURİ) Kırgız Türkçesinde "vurmak, çakmak" (Arıkoğlu vd., 2018: 696) anlamında kullanılıyor; gak- kak(İtmek, sokmak, saplamak -Çr) Kırgızcadakak-;gırç-, kırç- ( Kesmek, biçmek, -Isp) Kırgızcadakırç;, gırk-, kırk- (Kırkmak, -İç) Kırgızcadakırk-, (Zülfikar, 1995: 108-109) vb. Eğer bu fiiller yansımalı fiilse, Kırgız Türkçesinde kök halinde kullanılan yansımalı fiiller yok demek yanlış olur. Ancak Kırgız Türkçesindeki bu fiillerin yansıma olduğunu savunan ya da gramer kitaplarında yansıma olarak gösteren bir kaynağa rastlanmamışıı. Bu durumda aşağıdaki filler kök halinde kullanılan yansıma fiillerdir:

canç- : Ezmek, kırmak, vurmak, ufalamak (Arıkoğlu vd., 2018: 501). 
cır- : Yırtmak, yarmak, delmek (Arıkoğlu vd., 2018: 596).

clş- : Ovmak, ovalamak (Arıkoğlu vd., 2018: 598).

çak- : Kırmak, ezerek parçalamak (Arıkoğlu vd., 2018: 683).

çap- : Vurmak, çakmak (Arıkoğlu vd., 2018: 696).

kak- : Çakmak, vurarak sokup yerleştirmek (Arıkoğlu vd., 2018: 1051).

kırç- : Parçalayarak kesmek, bölmek (Arıkoğlu vd., 2018: 1237).

kırk- : Kesmek, kırkmak (Arıkoğlu vd., 2018: 1240). vb.

\subsubsection{Yardımcı Fiillerle Beraber Kullanımları}

Yansımalar çoğu zaman yardımcı fiillerle beraber kullanılır. Hamza Zülfikar'a göre fiil olarak kullanılmalarını sağlamak ve zamanlara göre çekimlerini yapabilmek için yardımcı fiillerden yararlanılmıştır.(Zülfikar, 1995: 93). Bu durumda yansımaların daha açık anlam kazandığını görülür. Kırgız Türkçesinde yansımaları yüklemleştirmekteet-, de-, bol-, kıl-, koy- yardımcı filleri kullanılır. En işlek ve hemen hemen bütün yansımalarla kullanılabilecek yardımcı fiiller et- ve de-' tir.

Kırgız Türkçesinde birincil biçim yansımaların fiil olarak kullanımında her zaman aynı yardımcı fiil veya tasfiri olmayan diğer fiillerle kullanılmaz. Yeri geldiğinde fiiller değişebilir bu da anlamı değiştirir. Örnek olarak cım yansımasını verecek olursak; clm bol- (1. Bilmiyormuş, haberi yokmuş gibi yaparak susmak, sessiz kalmak. 2. Sessizleşmek, sessiz olmak), cımcat(Sessizce yatmak), cım kül- (Gülümsemek), cım et- (Parlamak), cım de- (Mutlu olmak), cımdebe(Susmak, sesiz kalmak), cımdeytüş- (Aniden mutlu olmak, için için sevinmek), cım-cım (Pırıl pırıl, parıl parıl), clm-cım kül- (Gözleri parlayarak gülümsemek), clm-cım bol- (Gizlenmek, saklanmak, belirsiz kalmak), cımcım et- (Parlamak, 1şıldamak) vb. Bunun gibi Kırgız Türkçesinde aynı yansımayı farklı fiillerle beraber görmek mümkündür. $\mathrm{Bu}$ durumda yansımanın anlamı da değişmektedir.

\section{et- Fiiliyle Birincil Biçimler}

Kırgız Türkçesinde birincil biçimlerde kullanılan en işlek yardımcı fiil et- fiillidir. Hemen hemen bütün yansımalarda kullanılmaktadır. tüş- fiiliyle birlikte kullanımı da mevcuttur. Mesela, cark ete tüştü. Bu tür kullanımlar anlatıma aniden, birdenbire gibi anlamları katmaktadır.

bart et- : Kart gurt etmek (Arıkoğlu vd., 2018: 265).

bllk et- : Seğirmek, hafifçe oynamak (Arıkoğlu vd., 2018: 345).

cark et- : Parlamak, parıldamak (Arıkoğlu vd., 2018: 524).

dürt et- : Birdenbire yanmak (Arıkoğlu vd., 2018: 849).

selt et- : Korkudan dolayı ürpermek, sıçramak (Arıkoğlu vd., 2018: 1797).

kars et- : Tak, tok diye ses çıkmak (Arıkoğlu vd., 2018: 1130).

kort et- : Çabucak Kırılıvermek (Arıkoğlu vd., 2018: 1325).

künk et- : Açık konuşmamak bir şeyler söylenmek (Arıkoğlu vd., 2018: 1466). vb.

kll-Fiiliyle Birincil Biçimler.

Yardımcı fiillerin içinde en az kullanılan fiildir. Daha çok isim olarak kalıplaşmış yansımalarla görülür.

day kll- : Duyurmak, yaymak (Arıkoğlu vd., 2018: 783). 
düy kll- : Yaymak, birçok kimseye duyurmak (Arıkoğlu vd., 2018: 845).

bol- Fiiliyle Birincil Biçimler

cım bol- : Sessiz olmak, sessiz kalmak (Arıkoğlu vd., 2018: 593).

day bol- : Belli olmak, yayılmak (Arıkoğlu vd., 2018: 783).

düy bol- : Söz çıkmak, söylenti dolaşmak (Arıkoğlu vd., 2018: 845).

de- Fiiliyle Birincil Biçimler

et- fiilinden sonra gelen en işlek fiildir. Biçim yansımalarından daha az olmakla beraber ses yansımalarında daha çok görülür. Kullanım olarak geniş bir alan kapsamaktadır. Cümleler hem defiiliyle olumlu hem de debe- fiiliyle olumsuz olarak da kurulabilir. Ayrıca anlatıma ansızın, birdenbire, aniden anlamlarını katmak için tüş- fiiliyle birlikte de kullanılabilir.

şuu de- : 1. Pır diye ses çıkarmak. 2. Kalbi yerinden firlayacak gibi olmak (Arıkoğlu vd., 2018: 1916).

kıı de- : Ses vermek, herhangi bir ses çıkarmak (Arıkoğlu vd., 2018: 1233).

kııdebe- : Gıkı çıkmamak, gık dememek (Arıkoğlu vd., 2018: 1233).

kıık de- : İnlemek (Arıkoğlu vd., 2018: 1234).

kııkdebe- : Gıkı çıkmamak (Arıkoğlu vd., 2018: 1234).

cımdeytüş- : İçin için sevinmek, mutlu olmak (Arıkoğlu vd., 2018: 593).

çırtdeytüş- : Yüzü düşmek, somurtmak (Arıkoğlu vd., 2018: 733).

çurdeytüş- : Birdenbire gürültü koparmak (Arıkoğlu vd., 2018: 759).

duudeytüş- : Ansızın bir gürültü duyulmak (Arıkoğlu vd., 2018: 841).

düydeytüş- : Kısa sürede yaylmak, duyulmak (Arıkoğlu vd., 2018: 845).

dürdeytüş- : Titremek, korkuya kapılmak (Arıkoğlu vd., 2018: 847).

şılkdeytüş- : Birden bire aşagı doğru sarkıvermek, kafasının öne veya yana eğmek (Arıkoğlu vd., 2018: 1902).

Yansıma kelimeler, ikileme halinde de oldukça fazla kullanılırlar. İkilemeler her zaman eylemin daha kesin anlamlı ve canlı olmasını sağlar. Hareketin uzadığını, tekrarlandığını, birden fazla olduğunu gösterirler. Özellikle ikilemeyle beraber yardımcı fiil de kullanılırsa anlatım daha kesin ve daha zengin olur. En çok kullanılan yardımcı fiil et-ve bol-fiilleridir.

bıc-bıc et- : Kaynamak, mayalı bir şeyler kabarıp köpürmek (Arıkoğlu vd., 2018: 339).

bık-blk et- : Fıkır fikır etmek, kaynamak (Arıkoğlu vd., 2018: 342).

celp-celp et- : Dalgalanmak, kıpırdamak (Arıkoğlu vd., 2018: 558).

kü̈k-mıђk et- : Açık konuşmamak, mırıldanmak (Arıkoğlu vd., 2018: 1466).

çly-çuy et- : Cikcik etmek (Arıkoğlu vd., 2018: 735).

bas-bas bol- : Sakinleşmek, durmak (Arıkoğlu vd., 2018: 268).

bıt-çıt bol- : Paramparça olmak (Arıkoğlu vd., 2018: 352).

melt-kalt bol- : Dolup taşmak, gereğinden çok olmak (Arıkoğlu vd., 2018: 1539).

tım-tım bol-Susmak, sakinleşmek (Arıkoğlu vd., 2018: 2023). 
bas-bas kll- : Sakinleştirmek, yatıştırmak, durdurmak (Arıkoğlu vd., 2018: 268).

çıy-pıy kıl- : Alelacele sıcak ve hafif bir şeyler hazırlamak (Arıkoğlu vd., 2018: 735).

\subsection{4. Öteki Fiillerlle Beraber Kullanımları}

Kırgız Türkçesinde yansıma kökler, yardımcı fiiller dışında başka fiillerle beraber de kullanılır. Bu tür fiiller birincil biçim yansımaların anlamını tamamlamaktadır. Bu kullanım şekli ile yansımalar daha açık ve kesin bir anlam kazanırlar.

Kırgız Türkçesinde yansımalar anlatıma canlılık katan, anlatımı süsleyen, tamamlayan kelime türlerinden olduğu için herhangi bir fiil ile birlikte cümle içerisinde geçebilir. Yansımalar yapım ve çekim ekleriyle türeyebilen bir kelime kategorisi olduğundan öteki fiilllerle birlikte kullanımı daha çok birincil biçimlere aittir. Herhangi bir birincil biçim yansımayı diğer herhangi bir fiil ile görmek mümkündür. Mesela; karstiş- (ısır-), bors kül- (gülmek), şıp çık (çıkmak). Ancak, bazı fiiler yardımcı fiiller gibi çok sayıda da kullanılabiliyor. Örneğin, koy-, sal-, ber-, çık- vb.

koy- Fiiliyle Birincil Biçimler

cllt koy- : Birdenbire yok olmak, gözden kaybolmak (Arıkoğlu vd., 2018: 591).

kllt koy- : Birdenbire kaybolmak, ansızın sıvışmak (Arıkoğlu vd., 2018: 1228).

dir koy- : Hemen harekete geçmek veya birden kaçmak (Arıkoğlu vd., 2018: 815).

duu koy- : Birden ve hızlı bir şekilde hareket etmek (Arıkoğlu vd., 2018: 841).

ber- Fiiliyle Birincil Biçimler

cultber-: Birdenbire kaybolmak (Arıkoğlu vd., 2018: 591).

dirber-: Birden kaçmak (Arıkoğlu vd., 2018: 815).

sal- Fiiliyle Birincil Biçimler

duu sal- : Birden hızlı bir şekilde hareket etmek (Arıkoğlu vd., 2018: 841).

çuu sal- : Gürültü çıkarmak, koparmak (Arıkoğlu vd., 2018: 761).

çır sal- : Kavga çıkarmak (Arıkoğlu vd., 2018: 731).

çık- Fiiliyle Birincil Biçimler

çuu çık- : Gürültü kopmak (Arıkoğlu vd., 2018: 761).

çır çık- : Kavga çıkmak (Arıkoğlu vd., 2018: 731).

Diğer Fiilerle Birincil Biçimler

cark can- : Birdenbire alev almak, tutuşmak (Arıkoğlu vd., 2018: 524).

çark ur- : Firlamak, hızla bulunduğu yerden çıkmak (Arıkoğlu vd., 2018: 700).

çart kes- : Pat diye kesmek (Arıkoğlu vd., 2018: 702).

çortayt- : Kesin ve açık konuşmak (Arıkoğlu vd., 2018: 748).

tıp basıl-: Hemen durmak, hemen susmak, sesi kesilmek (Arıkoğlu vd., 2018: 2027) vb.

İkileme halinde genelde harekete ait bir fiille beraber kullanılırlar. İkilemeler eyleme uygun olarak birbirini tamamlarlar.

calt-calt kara- : Sürekli bakmak, bakınmak (Arıkoğlu vd., 2018: 492).

kürü-küütüş- : Gürültü çıkarmak (Arıkoğlu vd., 2018: 1473). 
oyko-çoyko at- : Takla atmak, devrilip yuvarlanmak (Arıkoğlu vd., 2018: 1638).

klt-kıt kül- : Kıkır kıkır gülmek (Arıkoğlu vd., 2018: 1248).

cım-cım kül- : Gözleri parlayarak gülümsmek (Arıkoğlu vd., 2018: 593).

\subsection{Türevler}

Yansıma kelimelerden de yeni isim ve fiiller türetilebilmektedir. Seminerimizde bu türetmede hangi eklerin daha çok kullanıldığ da görülmüş olacaktır. Bu grubu yansıma kelimelerden "İsimden İsim Yapma Ekleri"yle isim türetenler; yansıma kelimelerden "İsimden Fiil Yapma Ekleri”yle fiil türetenler şeklinde iki grup halinde ele alacağız.

\subsubsection{Yansıma Kelimelerden İsimden İsim Yapma Ekleriyle Kelime Türetenler:}

\subsubsection{Türetme/ Kuvvetlendirme}

Yansıma kelimelerde bildiğimiz isimden isim yapma eklerinden başka birde anlamı küvvetlendirdiğini düşündüğümüz birtakım seslerle de isim türetilmektedir. Mesela, $+\imath r(c ̧ a \eta+ı r)$, $+s(\operatorname{ar}+\mathbf{s}),+\mathrm{t}(\mathrm{kür}+\mathbf{t}),+\mathrm{k}(\mathrm{z} ı \mathfrak{y}+\mathbf{k})$. Bu tür sesler köklerden hemen sonra geldiği için bazen kökün devamı olarak bazen de bir ek olarak kabul edilmektedir. Ancak kökün devamı mıdır, ek midir

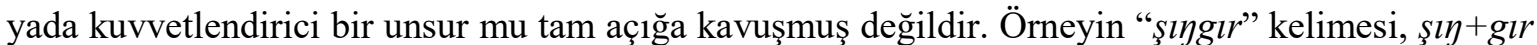

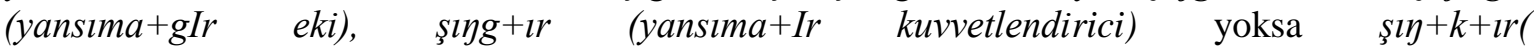
yansıma $+k k u v v e t l e n d i r i c i+ı r ~ e k i)$ midir tartışılabilir.

Ayrıca tırs, kürt, şart, kayk, tạk, vb. bu gibi CVCC kalıbındaki yansımaların son seslerini

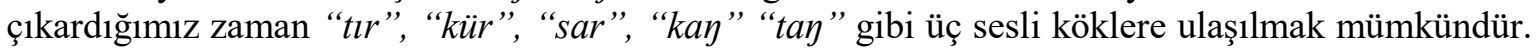
$\mathrm{Bu}$ üç sesli köklerden bir kısmı üç sesli olarak aynen ikileme veya yakın anlamlı ikileme olarak

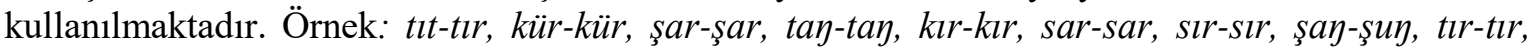
zır-zır vb. Ancak bu tür kelimelerin bazılarının üç sesli kök olarak kullanımı mevcut değildir. Kazak Türkçesiyle ilgili aynı durumdan bahseden Nergis Biray (2013: 1097) üç sesli örneklerin türevleriyle aralarında anlam birliği ve yakınlığının olması sebebiyle bu gibi seslerin anlamı kuvvetlendiren birer morfem olabileceğini söylemektedir.

$+\mathbf{I r}$

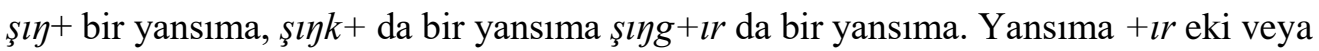
kuvvetlendiricisi anlamca güçlendirmiş. Bu türetme/kuvvetlendirme $(+t r)$ ile genişleyen şekiller tek başlarına çok kullanılmamakta farklı eklerle tekrar genişleyerek kullanım alanı kazanmaktadır.

şıng+ır / Şangırtı (Arıkoğlu vd., 2018: 1903).

şıng+ır+ak/ Çıngırak, zil sesi (Arıkoğlu vd., 2018: 1903).

$k \imath t+\boldsymbol{\imath}$ / Kitır ses (Arıkoğlu vd., 2018: 141).

şat+ır+ak / Sıvı, akışkan cisim (Arıkoğlu vd., 2018: 1894).

$b a d+\boldsymbol{\imath r}+a k$ / Patlamış mısır (Arıkoğlu vd., 2018: 221).

$+\mathbf{S}$

$a r+s$ / Köpeğin havlarken çıkardı̆̆ı ses (Ar1koğlu vd., 2018: 141).

$b o r+s$ / İnsan gülünce ve köpek havlayınca kısa ve kesik çıkan ses (Arıkoğlu vd., 2018: 392).

tor $+\mathbf{s}$ / Pat (Arıkoğlu vd., 2018: 2081).

$+\mathbf{t}$

“kür” yansımasına $+\mathrm{t}$ getirilerek kür+t. 
$k \ddot{u} r+\boldsymbol{t}+$ gü, kür+t+t+ük gibi tekrar genişletilmiş şekiller kullanılır.

$k a r+t$ / geğirme sırasında çıkan ses (Arıkoğlu vd., 2018: 1132).

şar+t / hemencecik, çarçabucak (Arıkoğlu vd., 2018: 1892).

$+\mathbf{k}$

Yine aynı şekilde sadece anlamca güçlendiriyor.

$k a \eta+k / 1$. Köpek veya kurtların çenilemesi. 2. Çın, çınlama sesi (Arıkoğlu vd., 2018: 1094).

$z a \eta+k$ / silahtan çıkan şiddetli ses, güm (Arıkoğlu vd., 2018: 2209).

$z ı \eta+k /$ zonk (Arıkoğlu vd., 2018: 2214).

$+\mathbf{p}$

düm+p : Altı boş yere basıldığında veya bir şeye vurulduğunda çıkan ses, küt (Arıkoğlu vd., 2018: 844).

$+\mathbf{c}$ 1120).

$k a r+c$ : Pat, sert bir şeyler kırıldığında veya çarpıştığında çıkan ses (Arıkoğlu vd., 2018:

$k \imath r+c$ : Kapı açılınca veya kara basıldığında çıkan ses (Arıkoğlu vd., 2018: 1237).

2.2.1.2. Ad Yapma Ekleriyle Türetilmiş Biçimler

$+\mathbf{A k} /+\mathbf{I k} /+\mathbf{O k} /+\mathbf{U k}$

$$
\text { İsim kökü + Ak / Ik / Ok / Uk- }
$$

balç+ık : Balçık, çamur (Arıkoğlu vd., 2018: 241).

kük+ük : Guguk kuşu (Arıkoğlu vd., 2018: 1453).

kürt+ük : Kürtün, kar yığını, tümseği (Arıkoğlu vd., 2018: 1473).

Fiil kökü -Ak / Ik / Ok / Uk-

tır-lk : Yara izi (Arıkoğlu vd., 2018: 2029).

cır-ık : Dudakları, burnu yarık, yırtık (Arıkoğlu vd., 2018: 597).

$+G U$

$$
\text { İsim kökü }+\mathrm{GU}
$$

kürt+gü : Kürtün, kar yığını (Arıkoğlu vd., 2018: 1473).

+ An / + In

$$
\text { İsim kökü }+ \text { An / In }
$$

şarp+ın : hlk. Akan suyun şarıltısı, şırıltısı (Arıkoğlu vd., 2018: 1893).

burk+anşark+an : 1. Gürleyerek, gürültülü. 2. Öfkeli, kızgın. (Arıkoğlu vd., 2018: 438).

$+\mathbf{I r} /+\mathbf{U r}$

bıç+ır : çatırt (Arıkoğlu vd., 2018: 341).

$b \imath d+\boldsymbol{r}$ : pürtük, küçük kabarcık (Arıkoğlu vd., 2018: 342).

balc+tr : salgı, salgı maddesi (Arıkoğlu vd., 2018: 343). 
boc+ur : devaml1, çok söylenen söz. (Arıkoğlu vd., 2018: 374).

$c ı b+\boldsymbol{r}$ : kabartılı, pürtüklü (Arıkoğlu vd., 2018: 577).

çat+ır : çatır(damak) (Arıkoğlu vd., 2018: 703).

$k u t+\boldsymbol{r}$ : kıtır ses (Arıkoğlu vd., 2018: 1248).

sölt+ür : sünepe, beceriksiz (Arıkoğlu vd., 2018: 1843).

tap+ır : tapır(damak) (Arıkoğlu vd., 2018: 1954).

$k \imath b+\boldsymbol{\imath}$ : Yavaş, hızlı olmayan, ağır (Arıkoğlu vd., 2018: 1216).

şald+ır : Takır tukur (Arıkoğlu vd., 2018: 1885).

$+\mathrm{II} /+\mathrm{Ul}$

ap+tl : Aceleyle, telaşla (Arıkoğlu vd., 2018: 120).

balb+ll : Alev alev, pırıl pırıl (Arıkoğlu vd., 2018: 239).

bülb+ül : Sönük, parlaklığı az (Arıkoğlu vd., 2018: 457).

dömb+ül : Tepe (Arıkoğlu vd., 2018: 833).

kap+ll : Aniden, ansızın (Arıkoğlu vd., 2018: 1098).

+Iș / Uș

$d a b+\iota s ̧$ : Ses, seda, ün (Arıkoğlu vd., 2018: 771).

şıb+ış : Çıtırtı (Arıkoğlu vd., 2018: 1900).

tıb+ış : Ses (Arıkoğlu vd., 2018: 2019).

+Ak / + Ik / +OK / + Uk

Yansıma isim kökünden isim türetir. Niteleme yapmakta ve sıfat göreviyle kullanılmaktadır.

$$
\text { İsim Kökü + Ir / Ur - Ak / Ik / Ok / Uk }
$$

$b a d+\imath r+a k$ : Patlamış mısır, kavrulmuş buğday veya arpa (Arıkoğlu vd., 2018: 221).

calt+ır+ak : Parlak, parıltı, pırıltı, 1ş1tı (Arıkoğlu vd., 2018: 492).

çın+ır+ık: Çı̆̆lık, feryat. (Arıkoğlu vd., 2018: 729).

çim+ir+ik: Topaç oyuncağı (Arıkoğlu vd., 2018: 738).

$k a l d+\imath r+a k$ : 1. Paldır küldür ses, çatırtı. 2. Kuru, kurumuş (Arıkoğlu vd., 2018: 1066).

$k a l t+\imath r+a k$ : Titrek, titreyen (Arıkoğlu vd., 2018: 1074).

$k \imath t+\imath r+a k$ : K1tır kıtır (Arıkoğlu vd., 2018: 1248).

$k o \eta+u r+u k$ : Horlama sesi (Arıkoğlu vd., 2018: 1313).

şıld+ır+ak : Çıngırak (Arıkoğlu vd., 2018: 1902).

$$
\text { İsim kökü + kIr / kUr -Ak / Ik / Ok / Uk }
$$

ar+kır-ak : Bağırarak yüksek sesle konuşan kimse (Arıkoğlu vd., 2018: 262).

bış+kır-ık : 1. T1ksırma, aksırma 2. Aniden gülme (Arıkoğlu vd., 2018: 352).

çüç+kür-ük : Aksırmak, hapşırmak. (Arıkoğlu vd., 2018: 761). 
ış+kır-ık : Düdük sesi, 1slık (Arıkoğlu vd., 2018: 977).

kat+kır-ık: Kahkaha (Arıkoğlu vd., 2018: 1146).

ke+kir-ik : Geğirme (Arıkoğlu vd., 2018: 1182).

koş+kur-uk : Atın ürktüğü zaman çıkardığı hırıltılı ses (Arıkoğlu vd., 2018: 1329).

tü+kür-ük : Tükürük (Arıkoğlu vd., 2018: 2129).

kür+kür-ök : Gürleme (Arıkoğlu vd., 2018: 1470).

şar+kir-ak : Şarıltı (Arıkoğlu vd., 2018: 1892).

$-\mathbf{k}$

$$
\text { İsim kökü +Il / +Ul + dA - k }
$$

+Il / Ul + dA- birleşik ekiyle fiil gövdesi olan yansıma kelimeler -k ekinin eklenmesiyle tekrar isim türetilir.

$a c+\imath l+d a-k:$ Ağı kavgası eden kimse (Arıkoğlu vd., 2018: 28).

$a \eta+l l+d a-k$ : Bağırıp çağıran, öfkeli (Arıkoğlu vd., 2018: 114).

$a \eta k+l l+d a-k$ : Sağına soluna bakmadan devamlı bağırıp kimse (Arıkoğlu vd., 2018: 116).

$b a c+l l+d a-k$ : Çok konuşan kimse (Arıkoğlu vd., 2018: 219).

$b a k+l l+d a-k$ : Gereksiz yere yüksek sesle çok konuşan kimse (Arıkoğlu vd., 2018: 229).

balb+ll+da-k: Parlak (Arıkoğlu vd., 2018: 239).

dük+ül+dö-k : Paldır küldür ses (Arıkoğlu vd., 2018: 843).

$t \imath k+\imath l+d a-k: 1$. Tıkırtı yapan. 2. Hızlı hareket eden kimse (Arıkoğlu vd., 2018: 2021).

$$
\text { İşim kökü + rA - k }
$$

+ra- ekinin yardımı ile yansıma fiil olan kelimeler -k ekini alarak tekrar isim, daha doğrusu sifat olabilmektedir.

maa+ra-k : Sürekli meleyen koyun, kuzu (Arıkoğlu vd., 2018: 1500).

möö+rö-k : Sürekli bögüren inek, öküz (Arıkoğlu vd., 2018: 157).

$$
\text { İsim kökü }+ \text { Ay / + Iy / + Oy / +Uy -k }
$$

Çoğu zaman biçim yansımalarında rastlanır. Kullanım olarak sıfat durumundadır. + Ay / Iy / Oy / Uy eklerinden sonra gelir. - $k$ ekinin gelmesiyle y- düşer. - $\eta$ eki için de aynı durum söz konusudur. Mesela; üksöy-, ,üksök, üksöy

$b \imath r b+\imath-k$ : Buruşmuş burun (Arıkoğlu vd., 2018: 346).

$s a k s+a-k$ : Saçları, tüyleri dağınık, kabarık (Arıkoğlu vd., 2018: 1761).

tayt $+a-k$ : Paytak, çarpık eğri bacaklı (Arıkoğlu vd., 2018: 1982).

tomp+o-k : Kabarık, şişkin, tombul (Arıkoğlu vd., 2018: 2069).

$-\eta \mathbf{\eta} / \tilde{\mathbf{n}}$

$$
\text { İsim gövdesi }+\mathrm{Ay} /+\mathrm{Iy} /+\mathrm{Oy} /+\mathrm{Uy}-\mathrm{y}
$$

İsimden isim yapar. $+n g>-\tilde{n}$ nöbetleşmesiyle ortaya çıkmış olabilir. Biçim yansımaları oluşturur. Kullanım olarak çoğu zaman sıfat durumundadır. + Ay / Iy / Oy / Uy- eklerinden sonra gelir ve $y$ 'sesi $y$ ekini alınca düşer. 
$b ı r b+\imath-\boldsymbol{\eta}$ : Her zaman ağlayacak gibi yüzünü burnunu buruşturan insan (Arıkoğlu vd., 2018: 346).

$s a k s+a-\boldsymbol{\eta}$ : Saçları, tüyleri dağınık (Arıkoğlu vd., 2018: 1761)

$-\mathbf{m A}$

$$
\text { İsim kökü +Ir / +Ur / +kIr / +kUr + A / +O / +I / +U- mA }
$$

$+A-,+O-,+I-,+U-$ ekleriyle isimden fiil türeten yansıma kelimeler bu gövdelerin üzerine -ma eki alarak tekrar isim türetirler:

caldır+a-ma : Anlamsız, garip durum, iradesiz cansız kimse (Arıkoğlu vd., 2018: 485).

şarkır+a-ma : Çağlayan, coşkun akan su (Arıkoğlu vd., 2018: 1892).

Ettirgenlik ekinden sonra da gelebilir.

şarkır+a+t-ma : Şelale (Arıkoğlu vd., 2018: 1892).

-ke

$$
\text { İsim kökü + Ay / Oy /Iy / Uy - ke }
$$

$+A y-,+O y-,+I y-,+U y$ - ekleriyle isimden fiil türeten yansima kelimeler bu gövdelerin üzerine -ke eki alarak tekrar isim türetirler. Bu durumda $-y$ düşer:

$a l c+a-k \boldsymbol{e}$ : Çok gevezelik eden, abuk sabuk konuşan (Arıkoğlu vd., 2018: 77).

balp+a-ke : Cömert, alicenap (Arıkoğlu vd., 2018: 246).

calc+a-ke : Budala (Arıkoğlu vd., 2018: 484).

\section{-GAy / -GIy}

$$
\text { İsim kökü + Ay / + Oy / +Iy / + Uy + -GAy / -GIy }
$$

$+A y-,+O y-,+I y-,+U y$ - ekleriyle isimden fiil türeten yansıma kelimeler bu gövdelerin üzerine -GAy eki alarak tekrar isim türetirler. Bu durumda -y düşer.

alc+a-gay : Büyük açılmış olan yaka veya delik (Arıkoğlu vd., 2018: 77).

aps+a-gay : Dağınık görünüşte olma (Arıkoğlu vd., 2018: 123).

balç+a-gay : Yassı ve yayvan (Arıkoğlu vd., 2018: 241).

balp+a-gay : Kilolu, yayvan (Arıkoğlu vd., 2018: 245).

bırb+l-gıy : Pat burun (Arıkoğlu vd., 2018: 346).

dürd+ü-güy : Kambur, çıkıntı (Arıkoğlu vd., 2018: 848).

$a d+\imath r+a-k a y$ : S1k1 olmayan (Arıkoğlu vd., 2018: 40).

$b a d+\imath r+a-k a y$ : İri (Arıkoğlu vd., 2018: 221).

$b a+k ı r+a-k a y$ : patlak göz, iri göz (Arıkoğlu vd., 2018: 230).

\section{+GAk}

1900).

şıbır+gak : S1k ve yoğun bir biçimde yağan kuru kar veya yağmur (Arıkoğlu vd., 2018:

- gAn

İsim kökü + Ay / Oy / Iy / Uy - GAn / GIn 
Fiil yapan $+A y_{-},+O y_{-},+I y-,+U y$ - eklerinin üzerine- $g A n$ eki gelerek tekrar isim türetilir. Sıfat durumunda kullanılır. $+A y-,+O y-,+I y-,+U y$ - ekiyle oluşmuş fillerden tekrar isim türetildiğinde $-y$ sesinin düşmediği, sadece bu ekle beraber kullanıldığında görülmektedir.

balt+ay-gan : Büyük, kocaman (Arıkoğlu vd., 2018: 248).

bıyp+ly-gan : Küçücük (Arıkoğlu vd., 2018: 354).

bolp+oy-gon : Tombul (Arıkoğlu vd., 2018: 380).

bölt+öy-gön : Kabarık, tombul (Arıkoğlu vd., 2018: 410).

tart+ay-gan : Eli ayag1 uzun (Arıkoğlu vd., 2018: 1965).

\section{+KAn}

Kalıplaşmış isim yapar.

babır+gan : Baykuşgiller türünden yırtıcı bir kuş (Arıkoğlu vd., 2018: 218).

bars+kan : Balyoz, ağır çekiç (Arıkoğlu vd., 2018: 265).

cıltır+kan : Hayvanların yediği çok yıllık yabani bir ot türü (Arıkoğlu vd., 2018: 592).

çuul+gan : Gürültü, bir çok kişinin karıştığı kavga (Arıkoğlu vd., 2018: 761).

kaldır+kan : 1. İri cins kelebek; 2. Teneke (Arıkoğlu vd., 2018: 1066).

şaldır+kan : 1. Çıngırak. 2. Eskimiş, eski püskü (Arıkoğlu vd., 2018: 1886).

$+\mathbf{t}$

$+I r,+U r$ eklerinden sonra gelir

$$
\text { İsim kökü + Ir / Ur + t }
$$

düb+ür+t : Patırtı, pat pat çıkan ses (Arıkoğlu vd., 2018: 842).

$k a \eta g+\imath r+t$ : Tingır (Arıkoğlu vd., 2018: 1093).

şı $b+\imath r+t$ : Çıtırtı (Arıkoğlu vd., 2018: 1900).

$+\mathrm{Oy}$

$+\mathrm{Il} /+\mathrm{Ul}$ eklerinden sonra gelir

$$
\text { İsim kökü + Il / Ul + On }
$$

dürb+öl+öy : 1. Kargaşa, karış1klık, gürültü 2. S1kıntı, telaş (Arıkoğlu vd., 2018: 847). top+ol+oy : Kargaşa, karışıklık (Arıkoğlu vd., 2018: 2076).

\subsubsection{Yansıma Kelimelerden İsimden Fiil Yapma Ekleriyle Kelime Türetenler:}

$+\mathrm{kIr}-$ / +kUr-

Kırgız Türkçesi'nde birincil biçimlerden fiil yapma ekleriyle türetilmiş yansımalı fiillerde +KIr-, +KUr-, eki önemli yere sahiptir.

ay+kır- : Haykırmak (Arıkoğlu vd., 2018: 190).

$b a+k ı r-:$ Bağırmak (Arıkoğlu vd., 2018: 230).

blş+kır- : 1.Tıksırmak, aksırma 2.Aniden gülme (Arıkoğlu vd., 2018: 352).

çüç+kür- : Aksırmak, hapşırmak (Arıkoğlu vd., 2018: 761).

ış+kır- : Düdük sesi, 1slık çalmak (Arıkoğlu vd., 2018: 977). 
kat+kir- : Kahkaha atmak (Arıkoğlu vd., 2018: 1146).

ke+kir-/ Geğirmek (Arıkoğlu vd., 2018: 1182).

koş+kur- : Atın ürktüğü zaman hırıltılı ses çıkartması (Arıkoğlu vd., 2018: 1329).

tü+kür- : Tükürmek (Arıkoğlu vd., 2018: 2129).

+lA- / +dA- / +tA-

Daha çok ikincil biçimlere has bir ektir. Az sayıda birincil biçimlerde de kullanılmaktadır.

aba+la- : Havlamak, durmadan havlamak. (Arıkoğlu vd., 2018: 19).

acaa+la- : 1. Havlamak, 2. karşısındakiye firsat vemeden sözle saldırmak (Arıkoğlu vd., 2018: 25).

çır-la- : 1. Kavga çıkarmak. 2. Huysuzluk etmek (Arıkoğlu vd., 2018: 733).

akak+ta- : 1. Yorulunca ve sicktan bunalınca sık sık solumak. 2. Susamak (Arıkoğlu vd., 2018: 56). Bu örnekte ikilemeli birincil biçim üzerine getirilmiştir.

çar+da- : 1. Kurbağa vaklamak 2. Kuş veya böcekler değişik tonda ses çıkarmak (Arıkoğlu vd., 2018: 699).

çır+da- : 1. Kavga çıkarmak. 2. Huysuzluk etmek (Arıkoğlu vd., 2018: 733).

+rA- / +rO-

maa+ra- : Koyun kuzu melemek (Arıkoğlu vd., 2018: 1500).

möö+rö- : İnek, öküz bögürmek (Arıkoğlu vd., 2018: 1573).

$+\mathbf{A} /+\mathbf{I} /+\mathbf{U}$

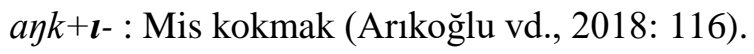

bılc $+\boldsymbol{l}$ - : Kötü, pis kokmak (Arıkoğlu vd., 2018: 343).

bılç+ı- : Dövmek, parçalamak, ezmek (Arıkoğlu vd., 2018: 344).

bükş+ü- : Kötü kokmak (Arıkoğlu vd., 2018: 456).

cılc+l- : Sizmak, sizarak akmak (Arıkoğlu vd., 2018: 583).

çak+a- : Boğazında kalmak (Arıkoğlu vd., 2018: 683).

çulg+u- : Kafasını sallamak (Arıkoğlu vd., 2018: 758).

kak+a- : Yemek boğazında kalmak, boğulmak (Arıkoğlu vd., 2018: 1053).

$k a k s ̧+a-:$ 1. Zırlamak, hıçkırarak ağlamak. 2. Durmada sürekli konuşmak (Arıkoğlu vd., 2018: 1057).

tant+r- : Saçmalamak, yersiz konuşmak (Arıkoğlu vd., 2018: 1949).

tayş+t- : 1. Ötmek, 2. Güzel ses çıkarmak, şarkı söylemek. (Arıkoğlu vd., 2018: 1952).

+ala- / +ele-

ant+ala- : Teleş etmek (Arıkoğlu vd., 2018: 109).

cac+ala- : Savunmaya çalışarak gereksiz yere konuşup durmak, lafi gevelemek (Arıkoğlu vd., 2018: 473).

ent+ele- : 1. Nefes nefese kalmak. 2. Afallamak (Arıkoğlu vd., 2018: 883). 
ile+ele - : Ağır ağır, yavaş yavaş yürümek (Arıkoğlu vd., 2018: 992). 1756).

sab+ala- : Hızlı, çabuçak, süretli, şidettli gitmek, uçmak, yağmak (Arıkoğlu vd., 2018:

talk+ala- : Kırmak, parçalamak, bozmak (Arıkoğlu vd., 2018: 1936).

tems+ele- : 1. Aradığı şeyi bulamayıp devamlı gezinmek. 2. Sendelemek (Arıkoğlu vd., 2018: 2001)

Ay / +Oy- / +Iy- / +Uy-

aクk+ay- : AğZı açık kalmak (Arıkoğlu vd., 2018: 115).

aps+ay- ; aps+ty- : Saçı sakalı birbirine karışmak (Arıkoğlu vd., 2018: 123).

$b a k+\boldsymbol{y}$ - : Büyük, kocaman, iri görünmek (Arıkoğlu vd., 2018: 231)

balk+ay- : İri yarı, büyük, tombul görünmek (Arıkoğlu vd., 2018: 244).

zınk+ıy- : 1. Ağır başlı ciddi olmak 2. Donmak, katılaşmak (Arıkoğlu vd., 2018: 2214).

+çAy- / +çIy- / +çOy / +çUy

çek+çey- : Dikilmek, belli bir noktaya uzun süre bakmak, (Arıkoğlu vd., 2018: 709).

çak+çay- : Gözlerini belitmek (Arıkoğlu vd., 2018: 684).

tık+çıy- : T1knazlaşmak, tıknaz olmak (Arıkoğlu vd., 2018: 2021).

+II- / +Ul-

send $+\boldsymbol{e l}$ - : Sendelemek (Arıkoğlu vd., 2018: 1799).

seys + el- : Sallanmak (Arıkoğlu vd., 2018: 1800).

$+\mathrm{Ir}-/+\mathrm{Ur}-$

cap+ır- : 1. Çiğnmek, ezmek. 2. Toplu olarak akın etmek (Arıkoğlu vd., 2018: 513).

capş+ır- : Çiğnemek, ezmek (Arıkoğlu vd., 2018: 515).

cım+ır- : Sahibine sormadan almak, çalmak, cebine indirmek (Arıkoğlu vd., 2018: 595).

çaク+ır- : Çı̆̆lık atmak vaya koparmak (Arıkoğlu vd., 2018: 695).

çıฤ+ır- : Çığlık atmak (Arıkoğlu vd., 2018: 729).

+lA- / +dA- / +tA-

$$
\text { İsim kökü + Ir / +Ur + 1A- }
$$

bıld $+\imath \boldsymbol{r}+\boldsymbol{l a}$ - : Mırıldanmak, anlaşılmayacak şekilde konuşmak (Arıkoğlu vd., 2018: 344).

$d a b+\imath r+l a-$ : Patır patır ses çıkarmak (Arıkoğlu vd., 2018: 770).

şab+ır+la- : Şakırdamak, hışırdamak, hış1ldamak (Arıkoğlu vd., 2018: 1882).

$$
\text { İsim kökü }+(\mathrm{A}) \mathrm{y}+\mathrm{dA} /+\mathrm{dO}-
$$

alc $+a \eta+d a-$ : Patavatsızlık etmek (Arıkoğlu vd., 2018: 77).

bagc $+a \eta+d a-:$ Neşeli keyifli halde olmak (Arıkoğlu vd., 2018: 223).

$$
\text { İsim kökü + Ir + (A) } \eta+\text { dA / +dO- }
$$

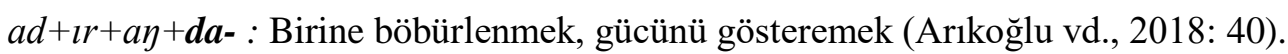


$60)$.

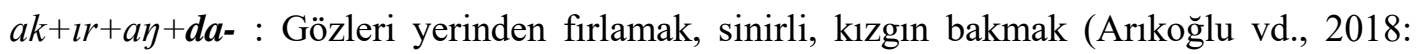

$b a c+\imath r+a \eta+d a-:$ Neşeli bir şekilde konuşmak, hareket etmek (Arıkoğlu vd., 2018: 219).

$$
\text { İsim kökü + (A)k + tA / +tO- }
$$

alc $+a k+t a-$ : Patavatsılık etmek (Arıkoğlu vd., 2018: 77).

bagc+ak+ta- : Neşeli keyifli halde olmak (Arıkoğlu vd., 2018: 223).

bal+ak+ta- : 1. Sallanmak. 2. Hüngür hüngür ağlamak (Arıkoğlu vd., 2018: 235).

$b a b+a k+t a-:$ Lapa lapa yağmak (Arıkoğlu vd., 2018: 218).

balp+ak+ta- : Agır ve sallanarak hareket etmek (Arıkoğlu vd., 2018: 246).

calc+ak+ta- : Yerli yersiz sürekli sırıtarak gülmek (Arıkoğlu vd., 2018: 484).

$$
\text { İsim kökü + Ir / +Ur + (A)k + tA / +tO- }
$$

$b a p+\imath r+a k+t a-:$ Morali yükselmek, neşelenmek (Arıkoğlu vd., 2018: 252).

cap $+\imath r+a k+$ ta $-:$ Parçalamak (Arıkoğlu vd., 2018: 513).

sand $+\imath r+a k+t a-: 1$. Haliz şekilde yürümek. 2. Saçmalamak (Arıkoğlu vd., 2018: 1776).

Kırgız Türkçesi'nde sadece biçim yansımalarda çok sık karşılaştığımız bir özellik vardır. Kökleri aynı olan $+\mathrm{A} \mathfrak{d}+\mathrm{dA}$ ve $+\mathrm{Ak}+\mathrm{tA}$ ekleriyle biten biçim yansımalarının anlam ve kullanım olarak birbirinden hiçbir farkı yoktur. Mesela, calcayda- ;calcakta-İkisi de "yerli yersiz gülmek, konuşmak, şaka yapmak" anlamını taşır ve ikisi de çok sık kullanılır. Birbirinden hiçbir farkı yoktur. Bir de aynı fiillerin araya giren -1A ekiyle kurulmuş şekilleri de vardır. Mesela,calcalaydacalcalakta-. İkisi de"çok rahat bir şekilde gülmek, şaka yapmak" anlamındadır. Yani anlam olarak diğer fiillerin biraz daha abartılmış, güçlendirilmiş halidir. Burada bir bakıma derecelendirme olduğunu düşünebiliriz.

$\mathrm{Bu}$ tür kullanımlar biçim yansımalarında çok sık rastlanmaktadır. Bazen sayı olarak fazla olmasıyla ya da sürekli tekrarlamamak amacıyla bu gibi aynı eylemin dört şekline de sözlüklerde rastlayamayabiliriz. Fakat bu tür kullanım özelliklerine halk ağzında daha çok rastlamak mümkündür. Ancak bu özellik $+A k+t A$-, $+A \eta+d A$ - ekleriyle biten bütün biçim yansımaları için geçerli anlamına gelmez.

barbayda-; barbakta-; barbalanda-; barbalakta- : Saf saf hareket etmek, sevinerek hareket etmek (Arıkoğlu vd., 2018: 256-257).

barpakta-; barpayda-; barpalayda-; barpalakta- : 1. Tüylerini uçuşturarak hareket etmek. 2. Sevinerek, neşeli hareket etmek (Arıkoğlu vd., 2018: 263-264).

dardayda-; dardakta-; dardalayda-; dardalakta- : Kaba, hantalca, hareket etmek (Arıkoğlu vd., 2018: 786-787).

kaldanda-; kaldakta-; kaldalayda-; kaldalakta- : 1. Kaba saba hareket etmek. 2. Telaşlanmak, acele etmek (Arıkoğlu vd., 2018: 1064-1065). vb.

$$
\text { İsim kökü + Il / +Ul+ dA / +dO- }
$$

$+l l,+i l,+u l,+\ddot{u} l$ sesleriyle biten yansima kelimelerden $+d A$ - eklerinin eklenmesiyle kullanmaktadır. Kırgız Türkçesinde kullanımı oldukça yaygındır.

$a c+l l+d a-:$ 1. Hiç durmadan havlamak. 2. Sözle saldırmak (Arıkoğlu vd., 2018: 28).

$a \eta+l l+d a-:$ Bağırıp çağırmak (Arıkoğlu vd., 2018: 114). 
$a \eta k+\imath l+\boldsymbol{d a}$ - : Oldukça yüksek sesle bağırmak (Arıkoğlu vd., 2018: 116).

$a p+l l+d a-:$ Yemeği aceleyle yemek (Arıkoğlu vd., 2018: 120).

$a r+l l+d a-$ : Bağırmak, haykırmak, kükremek (Arıkoğlu vd., 2018: 136).

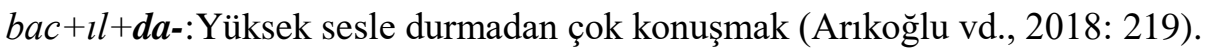

balb+ll+da- : 1. Alevlenmek 2. Parlamak 3. Tutuşup yanmak (Arıkoğlu vd., 2018: 239).

balç+ll+da- : Sırılsıklam olmak (Arıkoğlu vd., 2018: 241).

balk+ $\imath l+\boldsymbol{d a}$ - : Dolgun ve yumuşak olmak (Arıkoğlu vd., 2018: 244).

$+\mathbf{A} /+\mathbf{I} /+\mathbf{O} /+\mathbf{U}-$

İsim kökünden ve gövdesinden fiiller türetir. Yansımalarda en çok kullanılan fiil yapan ektir. Yansıma kelimenin verdiği anlamın hareket adını yapar.

$$
\text { İsim kökü }+\mathrm{Ir} /+\mathrm{Ur}+\mathrm{A} /+\mathrm{O} /+\mathrm{I} /+\mathrm{U}-
$$

alc $+\imath \boldsymbol{r}+\boldsymbol{a}$ - : Açılmak, gevşemek (Arıkoğlu vd., 2018: 77).

$b a c+\imath r+a-:$ Neşeli şekilde çok konuşmak (Arıkoğlu vd., 2018: 219).

$b a c ̧+\imath r+a-:$ Çatırdamak (Arıkoğlu vd., 2018: 220).

$b a d+\imath r+a-:$ Patlamak, gümremek (Arıkoğlu vd., 2018: 221).

balb+ır+a- : Yumuşamak (Arıkoğlu vd., 2018: 239).

balc $+\imath r+a-:$ Koyu ve yapışkan olmak (Arıkoğlu vd., 2018: 240).

büc $+\ddot{u} r+\ddot{o}-$ : 1. Küçük adımlarla çok dikkatli yürümek. 2. Büzülmek, korku, şaşkınlık, soğuk vb. etkenlerden bir enara çekilmek (Arıkoğlu vd., 2018: 453).

$$
\text { İsim kökü }+ \text { GIr / +GUr + A / +O / + I / +U - }
$$

$a \eta+g \imath r+a-:$ Olanca gücüyle, sesi yettiğince bağırmak (Arıkoğlu vd., 2018: 114).

$a r+k \imath r+a-$ : Kükremek, uğuldamak, gürlemek (Arıkoğlu vd., 2018: 140).

car $+k i r+a-:$ Parlak olmak (Arıkoğlu vd., 2018: 525).

790).

$d a r+k ı r+a-:$ 1. Bağırtı, yüksek ses çıkarmak. 2. Gırtlaktan konuşmak (Arıkoğlu vd., 2018:

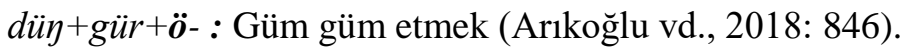

dür+kür+ö- : 1. Gürlemek 2. Toplu halde şak sesi çıkarmak (Arıkoğlu vd., 2018: 848).

$\imath r+k \imath r+\boldsymbol{a}$ - : Hırlamak, uğuldamak (Arıkoğlu vd., 2018: 973).

$k a \eta+g ı r+a-:$ 1. Boş kalmak, 2. Güm güm ses çıkmak (Arıkoğlu vd., 2018: 1093).

$z ı \eta+g \imath r+a-:$ 1. Ağır başlı ciddi olmak 2. Zonklamak (Arıkoğlu vd., 2018: 2214).

+Ay- / +Oy- / +Iy- / +Uy-

$$
\text { İsim kökü + Ir / Ur + Ay- / +Oy- / + Iy- / +Uy - }
$$

$a k+\imath r+a y-:$ Gözlerini genişçe açarak sinirlice bakmak (Arıkoğlu vd., 2018: 60).

$a \eta+\imath r+a y-:$ 1. Ardına kadar açılmak 2. Ağzı açık kalmak (Arıkoğlu vd., 2018: 115).

$b a c+\imath r+a y-:$ Gözler büyük fal taşı gibi açılmak (Arıkoğlu vd., 2018: 220). 


\section{Sonuç}

Yukarıda verilen örneklerden hareketle şu değerlendirmeleri yapabiliriz:

- Yapı bilgisi açısından yansımalar aktif bir şekilde kelime türetmeye meyillidir. Hatta yansımaların sayesinde Kırgız Türkçesi söz hazinesinde yer alan kelimeler daha da artmaktadır. Yansımalar kelime türetme yolları ile başka kelime türlerine geçebilirler, ancak başka türden olanlar yansıma olamazlar. Sonuna hangi ek gelirse gelsin kökü her zaman bir yansımadan ibarettir. Yansımalar çeşitli eklerle isim, fiil, sıfat ve zarf olabilirler. Bu özelliğini her zaman korumaktadırlar.

- Kırgız Türkçesinde birincil biçim yansımaların doğrudan fiil olarak kullanımı çok azdır. Daha çok yardımcı ve öteki fiillerle beraber kullanılmaktadır. En çok kullanılan yardımcı fiil etfiilidir.

- Yansıma kelimelerden İsim yapan ekler: İlk olarak kuvvetlendirme olduğu düşünülen bazı sesler vardır. Mesela, $+\mathrm{s}(a r+s, k a r+s),+\mathrm{t}(s ̧ a r+t, k a r+t),+\mathrm{k}(d \ddot{u} \eta+k, z o \eta+k),+\mathrm{p}$ $($ tom $+p$, düm $+p),+c ̧(k a r+c ̧, k \imath r+c ̧)$ vb.Daha sonra $+\mathrm{Ak} /+\mathrm{Ik} /+\mathrm{Ok} /+\mathrm{Uk}(k \ddot{u} k+\ddot{u} k, b a l c ̧+l k)+\mathrm{An} /$ $+\mathrm{In}($ şarp $+\imath n$, burk $+a n),+\mathrm{gU}(k u r t+g \ddot{u}),+\mathrm{Ir} /+\mathrm{Ur}(k \imath b+\imath r$, şald $+\imath r),+\mathrm{Il} /+\mathrm{Ul}(d \ddot{m} m b+\ddot{u} l, b a l b+\imath l)$, $+\mathrm{Iş} \mathrm{/} \mathrm{+Uş}(s ̧ \iota b+\imath s ̧, t \imath b+\imath$ ş) ekleri dişında, +Ak / + $\mathrm{Ik} /+\mathrm{Ok} /+\mathrm{Uk}(b a d+\imath r+a k, k o \eta+u r+u k$,

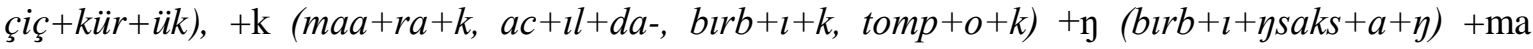
$(c a l d+\imath r+a-m a, s ̧ a r k+\imath r+a-m a), \quad-k e(a l c+a-k e, b a l p+a-k e)$, -Kay (adar+a-kay, dürd $+\ddot{u}-g u ̈ y),-$ gAn (balt+ay-gan, bölt+öy-gön $), \quad+\mathrm{Gak}(s ̧ b+\imath r+g a k)+\mathrm{KAn}(b a b+\imath r+g a n, \quad k a l d+\imath r+k a n)+\mathrm{t}$ $(s ̧ l b+\imath r+t$, düb $+\ddot{u} r+t)+\mathrm{O \eta}(t o p+o l+o \eta, d \ddot{u} r b+\ddot{o} l+\ddot{\eta} \eta)$

- Yansımalardan Fiil yapan ekler. +kIr- / +kUr- $(b a+k l-r, c ̧ u ̈ c ̧+k u ̈ r-),+1 \mathrm{~A}-/+\mathrm{dA}-/+\mathrm{tA}-$ $(c ̧ a r+d a-, a c a+l a, a k a k t a-),+\mathrm{rA}-/$ +rO- $(m a a+r a-, m \ddot{o} o ̈+r o ̈-),+\mathrm{A}-/+\mathrm{I}-/+\mathrm{O}-/+\mathrm{U}-(k a k+a-$, çum $+u$-, tant $+l-),+\mathrm{AlA}-($ tagk+ala-, ent + ele- $),+\mathrm{Ay}-/+\mathrm{Iy}-/+\mathrm{Oy}-/+\mathrm{Uy}-($ balk + ay-, zı $k+\imath y-$ ), +çAy- / +çIy- / +çOy- / +çUy- (çek+çey-, çak+çay-, tzk+çıy-, çok+çoy-), +lA- / +dA- I +tA$(s ̧ a b+\imath r+l a-, \quad a k+\imath r+a-\eta+d a-, \quad b a b+a k+t a-, \quad a \eta+\imath l+d a-, \quad b a l b+\imath l+d a-),+\mathrm{A}-1+\mathrm{I}-1+\mathrm{O}-1+\mathrm{U}-$

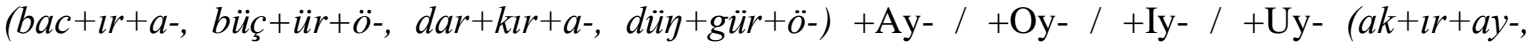
$b a k+\imath r+a y-)$.

- Elde ettiğimiz örneklerden harekete yansıma sözcüklerden isim türetme sisteminin daha az kullanıldığı, daha çok fiil türetildiği sonucunu söylemek mümkündür. İsim türettiğini düşündüğümüz bazı ekler sadece anlamı kuvvetlendirmektedir. Yansıma kelimelerde önemli olan sesin daha yüksek, daha vurgulu, vs. kullanıldığını gösterme işi, bu ekler veya kuvvetlendiricilerle yapılmaktadır.

Buradan çıkan sonuca göre yansımalar isim kökleri olarak daha çok aldıkları eklerle fiil türetmeye uygundurlar. İsim türetiminde daha çok anlamın kuvvetlendirilmesi için ek kullanılmaktadır. Getirilen ekler az da olsa anlamda değişime sebep olmaktadır. Örneğin: şıng+ır gibi.

$\mathrm{Bu}$ açıdan ele alındığında yansıma sözlerin de dilin vazgeçilmez unsurları olarak diğer isimler kadar olmasa da kelime türetimine katkıda bulunduğunu belirtmek mümkün olacaktır. 


\section{Kaynakça}

Abduldayev, E., İsayev, D. (1969). Kırgız TilininTüşündürmöSözdügü. Mektep.

Abduvaliyev, İ. (2008). Kirgız TilininMorfologiyast. PoligrafResurs.

Abduvaliyev, İ., Sadıkov, T. (1997). Azırkı Kırgız Tili. Morfologiya. Aybek.

Akunova, A. (2009). AzırkıkırgızTili, Morfologiya. Maxprint.

Arıkoğlu, E., Alimova, C., Askarova, R., Selçuk, B. (2018). Kırgızca-Türkçe Sözlük 1. Bengü Yayınları.

Arıkoğlu, E., Alimova, C., Askarova, R., Selçuk, B. (2018). Kırgızca-Türkçe Sözlük 2. Bengü Yayınlar1.

Banguoğlu, T. (2015). Türkçenin Grameri. Türk Dil Kurumu Yayınları.

Baytok, A. (2014). "Kırgız Türkçesinde Yansımalı Sözcükler ve Lehçeler arası

Aktarmadaki Önemi”, Modern Türklük Araştırma Dergisi, 11(3), 106-145. http://dx.doi.org/10.1501/MTAD.11.2014.3.34

Baytursunov, A. (1992). TilTagilımı.

Biray, N. "Kazak Türkçesinde Yansımalı İkilemeler - Ses Özellikleri Bakımından”.

VI. Dünya Dili Türkçe Sempozyumu, 2. 1091-1105. (Tam Metin Bildiri/) (Yayın No:1353036) ISBN- 978-605-9968-20-1

Davletov, S., Kudaybergenov, S. (1980). Azırkı Kırgız Tili, Morfologiya.

Diykanov, K. (1990). Kırgız Tilinin Körsötmö Kuraldarı. Üniversite yayınlar.

Ediskun, H. (1999). Türkçe Dilbilgisi. Remzi Kitabevi.

Ergin, M. (1958). Türk Dil Bilgisi. İ. Ünv. Ed. Fak. yayını.

Gencan, T. (1975). Dilbilgisi. Türk Dil Kurumu Yayınları.

Hatiboğlu, V. (1971). Türk Dilinde İkileme. TDK yay.

Hatiboğlu, V. (1978). Dilbilgisi Terimleri Sözlüğ̈̈. Dil Tarih Coğrafya Fakültesi Yayınları.

Hengirmen, M. (1995). Türkçe Dil Bilgisi. Engin Yayınevi.

İmanaliyev, S. (1969). Kırgız Tilindegi Strdık Sözdör.

İmer, K., Kocaman, A., Özsoy, S. (2011). Dilbilim Sözlüğü. Boğaziçi Üniversitesi Yayınevi.

Karahan, L. (2008). "Tekrar Gruplarında Ünlü Düzeni - Analam İlişkisi Üzerine Düşünceler" Prof, Dr. Ahmet Bican Erculasun Armağanı. (Editor, Ekrem Arıkoğlu). Akçağ yay. 140143.

Karahan, F. (2011) “Çağdaş Türk Lehçelerinde Yansıma Kelimeler” Kafkas Üniversitesi, Yüksek Lisans Tezi.

Kerimcanova, B. (1940). Kırgız TilindegiTuurandı cana Sirdık Sözdördün Grammatikalık Özgöçölügü.

Korkmaz, Z. (2009). Türkiye Türkçesi Grameri (Şekil Bilgisi). Türk Dil Kurumu Yayınları.

Kudaybergenov, S. (1957). PodrajatelnıyeSlova v KırgızskomYazıke. Kırgızuçped.

Kudaybergenov, S. (1980). Kırgız Adabiy Tilinin Grammatikası. İlim. 
Kudaybergenov, S.(1981). Kırgız Tilindegi Elestü̈̈ Etişter. İlim.

Oruzbayeva, B. (2009). Azırkı Kırgız Adabiy Tili. Çıngız Aytmatov Atındagı Til cana Adabiyat İnstitutu.

Tinıstanov, K. (1934). Kırgız Tili.

Vardar, B. (2002). Açıklamalı Dilbilim Terimleri Sözlüğü, Multilingual Yabancı Dil Yayınları.

Yudahin, Kostantin (1965). Kirgizsko-Russkiy Slovar 1. Sovetskaya Ensiklopediya.

Yudahin, Kostantin (1965). Kirgizsko-Russkiy Slovar 2. Sovetskaya Ensiklopediya.

Yudahin, Kostantin (1998). Kırgız Sözlüğ̈̈ 1. (Çev. Abdullah Taymaz) Türk Dili Kurumu Yayınlar1.

Yudahin, Kostantin (1998). Kırgız Sözlüğ̈̈ 2.. (Çev. Abdullah Taymaz) Türk Dili Kurumu Yayınları.

Yunusaliyev, B. (1959). Kırgızskaya Leksikologiya. İlim.

Yunusaliyev, B. (1985). Tandalgan Emgekter. İlim.

Zülfikar, H. (1995). Türkçede Ses Yansımalı Kelimeler. Türk Dil Kurumu Yayınları. 